\title{
Impact of Pulmonary Rehabilitation Program on Respiratory Function and Exercise Tolerance in Subjects with Down Syndrome
}

\author{
Riziq Allah Mustafa Gaowgzeh ${ }^{1}$, Mohamed Faisal Chevidikunnan ${ }^{2 *}$, \\ Fayaz Rahman Khan ${ }^{3}$ \\ ${ }^{1,3}$ Assistant Professor, Department of Physical Therapy \\ Faculty of Applied Medical Sciences, King Abdulaziz University, Jeddah, Saudi Arabia. \\ ${ }^{2}$ Lecturer, Department of Physical Therapy \\ Faculty of Applied Medical Sciences, King Abdulaziz University, Jeddah, Saudi Arabia.
}

\begin{abstract}
:
Background: Down syndrome subjects complain of many pulmonary dysfunctions that adversely affect the general health and quality of life.

Objective: The aim of this study was to detect the effect of pulmonary rehabilitation program on respiratory functions and exercise tolerance in Down syndrome subjects.

Subjects and Methods: Forty Down syndrome subjects (22 males and 18 females) with age ranged from 18-25 years and IQ level ranged from 55-65\% were enrolled in the present study and were assigned into two equal groups, group (A) received pulmonary rehabilitation program included breathing exercises via resisted diaphragmatic breathing by abdominal weights in addition to aerobic exercise on treadmill 3 times per week for successive 2 months, while group $(B)$ received no intervention and was considered as a control group. Measurements of vital capacity $(V C)$, maximum voluntary ventilation $(\mathrm{MVV})$, arterial oxygen saturation $\left(\mathrm{SaO}_{2}\right)$, maximum oxygen consumption $\left(\mathrm{VO}_{2}\right.$ max.) and respiratory rate (RR) were taken before the study and after the end of the study. Results: The mean values of $V C, M V V, \mathrm{SaO}_{2}$ and $\mathrm{VO}_{2}$ max were significantly improved and RR significantly decreased in group (A), while changes were not significant in group (B). In addition, there were significant differences between mean levels of the investigated parameters of group (A) and group (B) at the end of the study.
\end{abstract}

Conclusion: Pulmonary rehabilitation program improves respiratory function and exercise tolerance in Down syndrome subjects.

Keywords: Pulmonary Rehabilitation, Pulmonary Function, Exercise Tolerance, Down syndrome.

\section{Introduction}

Down syndrome (DS) is a chromosomal disorder resulting in various abnormalities such as mental retardation, immunodeficiency and physical abnormities [1]. Trisomy 21 is the other term used to refer for this disorder which occurs in 1:800 live birth, as the faulty cell division affecting the twenty first pair of chromosomes[1,2].The extra chromosomal 21 after almost every organ resulting in a multi system disorder such as, neuromotor, musculoskeletal, cardiopulmonary and a wide spectrum of life threatening complications [3].

Subjects with DS who are free from pulmonary disorder, congenital heart disorders, or endocrine diseases are usually suffer from limitation in work performance even during simple tasks than subjects without DS at all life stages [4-6]. This is usually detected via lower value of $\mathrm{VO}_{2 \max }$, which ultimately shows reduction in exercise capacity may adversely affects their quality of life and induces rapid and early feeling of fatigue [715]. Down syndrome subjects have an excess of respiratory problems due to many contributing factors such as immune dysfunction, hypotonia, neuromuscular weakness of respiratory muscles that lead to low vital capacity with decreased ventilatory pump. Along with this, immune dysfunction also might account for the high incidence of respiratory problems commonly seen in subjects with Down syndrome [16]. Respiratory therapy helps to restore or maintain the cardio-respiratory functions in DS subjects who have respiratory problem due to neurological, musculoskeletal and impaired ventilatory pump [17]. However, upper and lower limb exercise trainings are the main components of any pulmonary rehabilitation program. The effects of combined inspiratory muscle training and upper limb exercise in the form of cycle ergometer training for 8 weeks increased the maximal power output and oxygen intake [18]. So, this study was aimed to determine the effect of pulmonary rehabilitation program on respiratory function and exercise tolerance in subjects with Down syndrome. 


\subsection{Subjects:}

\section{Materials And Methods}

Forty Down syndrome subjects (22 males and 18 females) with age ranged from 18-25 years and IQ level ranged from $55-65 \%$ were enrolled in the present study and they were assigned into two equal groups. Group (A) received pulmonary rehabilitation program which included breathing exercises via resisted diaphragmatic breathing by abdominal weights in addition to aerobic exercise on treadmill 3 times per week for successive two months, while group (B) received no intervention and was considered as the control group. Patients with musculoskeletal, neurological, cardiac or respiratory disorders were excluded from the study.

\subsection{Methods:}

\section{Equipments Used:}

1. Spirometer (Spirovit, Sp-10, Switzerland): It was a computerized apparatus used for recording forced vital capacity (VC), maximum voluntary ventilation (MVV) and arterial oxygen saturation $\left(\mathrm{SaO}_{2}\right) \cdot \mathrm{SaO}_{2}$ was measured with a special sensor which is attached to the same equipment [19, 20].

2. Cardiopulmonary exercise test unit (Zan 800, Germany): The continuous progressive exercise tolerance test was applied following the Bruce standard protocol, that consists of warming up phase and five active phases and recovery phase to detect maximal oxygen consumption $\left(\mathrm{VO}_{2 \text { max. }}\right)$.

3. Abdominal weights: It was used for resistive breathing exercise training. It is a bag contains sand at different weights which are comes with velcro straps to be applied firmly. Their weights were graduated according to patient's ability.

4. Treadmill (Enraf Nonius, Model display panel Standard, Nr 1475.801, Holland) was used in performance of walking exercises.

\section{Procedures:}

1. The Experimental Group (Group A): Participants of group (A) received pulmonary rehabilitation program in the form of:

i) Resisted Breathing Exercises: Resisted diaphragmatic breathing was applied using weighted sand bags that placed on a folded Turkish towel to prevent friction between weights and skin of the subjects and the weights were placed on the epigastric region. The subjects were made to lie in supine and directed to do the breathing exercises. Inspiratory muscle training was done for 8 weeks with progressively increasing weights with $2 \mathrm{Kgs}$ during $1^{\text {st }} \& 2^{\text {nd }}$ week, $3 \mathrm{Kgs}$ during $3^{\text {rd }} \& 4^{\text {th }}$ week, $4 \mathrm{Kgs}$ during $5^{\text {th }} \& 6^{\text {th }}$ week and $5 \mathrm{Kgs}$ during $7^{\text {th }} \& 8^{\text {th }}$ weeks. Each session lasted for 30 minutes per day for six days per week for a period of 8 weeks $[21,22]$.

ii) Treadmill Exercises: Participants of group (A) used treadmill for exercising and strengthening the muscles of lower limbs as well as for walking test. Training program divided into 10 minutes of warm up, 30 minutes of walking training and 10 minutes to cool down. Patients were made to stand in front of a mirror, the speed at zero inclination was $400 \mathrm{~m} / \mathrm{second}$ and intensity of the exercise training was $60 \%-80 \%$ of maximum heart rate, which was given for three days per week until the end of the study.

Measurements of VC, MVV, $\mathrm{SaO}_{2}, \mathrm{VO}_{2 \max }$ and $\mathrm{RR}$ were taken before the study and repeated at the end of the study ie, after two months.

2. The Control Group (Group B): Participants received no intervention.

\section{Statistical Analysis and Results}

The mean values of the investigated parameters were detected at the beginning and at the end of two months of study for both groups and they were compared by using student paired "t" test. And, the unpaired " $\mathrm{t}$ " test was used to do the comparisons between the two groups $(\mathrm{P}<0.05)$.

The baseline and anthropometric characteristics of the subjects are shown in Table 1. There was no significant difference in the mean value of the age, height, body weight, body mass index (BMI), waist circumference, fat mass, systolic blood pressure (SBP) and diastolic blood pressure (DBP) between both groups. 
Table 1: Comparison of Baseline and Anthropometric variables between the group (A) and (B).

\begin{tabular}{|l|c|c|}
\hline & Group (A) & Group (B) \\
\hline Age (years) & $21.27 \pm 3.43$ & $20.96 \pm 3.52$ \\
\hline Height $(\mathrm{cms})$ & $163.22 \pm 6.81$ & $165.14 \pm 7.19$ \\
\hline Body Weight $(\mathrm{kg})$ & $66.15 \pm 5.17$ & $65.26 \pm 5.83$ \\
\hline BMI $\left(\mathrm{kg} / \mathrm{m}^{2}\right)$ & $24.23 \pm 2.11$ & $22.87 \pm 2.36$ \\
\hline Waist Circumference $(\mathrm{cms})$ & $77.13 \pm 4.63$ & $75.65 \pm 4.39$ \\
\hline Fat Mass $(\mathrm{Kgs})$ & $15.16 \pm 2.51$ & $14.38 \pm 2.74$ \\
\hline SBP $(\mathrm{mm} \mathrm{Hg})$ & $123.14 \pm 10.53$ & $121.22 \pm 11.18$ \\
\hline DBP $(\mathrm{mm} \mathrm{Hg})$ & $78.25 \pm 7.12$ & $77.15 \pm 6.96$ \\
\hline
\end{tabular}

BMI: Body Mass Index; SBP: Systolic Blood Pressure; DBP: Diastolic Blood Pressure.

The mean values of $\mathrm{VC}, \mathrm{MVV}, \mathrm{SaO}_{2}$ and $\mathrm{VO}_{2}$ max were significantly improved and $\mathrm{RR}$ significantly decreased in group (A) (Table 2), while changes were not significant in group (B) (Table 3). In addition, there were significant differences between mean levels of the investigated parameters of group (A) and group (B) at the end of the study (Table 4).

Table 2: Mean value and significance of $\mathrm{VC}, \mathrm{MVV}, \mathrm{SaO}_{2}, \mathrm{VO}_{2 \max }$ and $\mathrm{RR}$ of group (A) before and at the end of the study.

\begin{tabular}{|l|c|c|c|}
\hline \multirow{2}{*}{} & \multicolumn{2}{|c|}{ Mean \pm SD } & \multirow{2}{*}{ Significance } \\
\cline { 2 - 3 } & Before & After & \\
\hline $\mathrm{VC}(\%)$ & $75.16 \pm 6.25^{*}$ & $87.34 \pm 7.54$ & $\mathrm{P}<0.05$ \\
\hline $\mathrm{MVV}(\mathrm{L} / \mathrm{min})$ & $81.24 \pm 7.48^{*}$ & $98.15 \pm 8.69$ & $\mathrm{P}<0.05$ \\
\hline $\mathrm{SaO}_{2}(\%)$ & $90.57 \pm 4.12^{*}$ & $95.86 \pm 4.53$ & $\mathrm{P}<0.05$ \\
\hline $\mathrm{VO}_{2}$ max. & $31.18 \pm 2.41^{*}$ & $37.27 \pm 2.14$ & $\mathrm{P}<0.05$ \\
\hline $\mathrm{RR}$ (breath/min.) & $25.23 \pm 2.67^{*}$ & $20.13 \pm 2.19$ & $\mathrm{P}<0.05$ \\
\hline
\end{tabular}

VC: Vital Capacity; MVV: Maximum Voluntary Ventilation; $\mathrm{SaO}_{2}$ : Arterial Oxygen Saturation; $\mathrm{VO}_{2} \mathrm{max}$ : Maximum Oxygen Consumption; RR: Respiratory Rate; (*) indicates a significant difference, $\mathrm{P}<0.05$.

Table 3: Mean value and significance of $\mathrm{VC}, \mathrm{MVV}, \mathrm{SaO}_{2}, \mathrm{VO}_{2} \mathrm{max}$ and $\mathrm{RR}$ of group (B) before and at the end of the study.

\begin{tabular}{|l|c|c|l|}
\hline \multirow{2}{*}{} & \multicolumn{2}{|c|}{ Mean \pm SD } & \multirow{2}{*}{ Significance } \\
\cline { 2 - 4 } & Before & After & \\
\hline $\mathrm{VC}(\%)$ & $74.38 \pm 7.21$ & $73.25 \pm 7.22$ & $\mathrm{P}>0.05$ \\
\hline $\mathrm{MVV}(\mathrm{L} / \mathrm{min})$ & $80.26 \pm 8.13$ & $79.94 \pm 8.11$ & $\mathrm{P}>0.05$ \\
\hline $\mathrm{SaO}_{2}(\%)$ & $91.23 \pm 3.96$ & $91.12 \pm 3.98$ & $\mathrm{P}>0.05$ \\
\hline $\mathrm{VO}_{2}$ max. & $30.85 \pm 2.54$ & $30.57 \pm 2.46$ & $\mathrm{P}>0.05$ \\
\hline $\mathrm{RR}$ (breath/min.) & $25.41 \pm 2.52$ & $26.18 \pm 2.54$ & $\mathrm{P}>0.05$ \\
\hline
\end{tabular}

VC: Vital Capacity; MVV: Maximum Voluntary Ventilation; $\mathrm{SaO}_{2}$ : Arterial Oxygen Saturation; $\mathrm{VO}_{2}$ max: Maximum Oxygen Consumption; RR: Respiratory Rate; $\mathrm{P}<0.05$.

Table 4: Mean value and significance of $\mathrm{VC}, \mathrm{MVV}, \mathrm{SaO}_{2}, \mathrm{VO}_{2}$ max and $\mathrm{RR}$ of group (A) \& (B) at the end of the study.

\begin{tabular}{|l|c|c|c|}
\hline \multirow{2}{*}{} & \multicolumn{2}{|c|}{ Mean \pm SD } & \multirow{2}{*}{ Significance } \\
\cline { 2 - 4 } & Group (A) & Group (B) & \\
\hline $\mathrm{VC}(\%)$ & $87.34 \pm 7.54^{*}$ & $73.25 \pm 7.22$ & $\mathrm{P}<0.05$ \\
\hline $\mathrm{MVV}(\mathrm{L} / \mathrm{min})$ & $98.15 \pm 8.69^{*}$ & $79.94 \pm 8.11$ & $\mathrm{P}<0.05$ \\
\hline $\mathrm{SaO}_{2}(\%)$ & $95.86 \pm 4.53^{*}$ & $91.12 \pm 3.98$ & $\mathrm{P}<0.05$ \\
\hline $\mathrm{VO}_{2}$ max. & $37.27 \pm 2.14^{*}$ & $30.57 \pm 2.46$ & $\mathrm{P}<0.05$ \\
\hline $\mathrm{RR}$ (breath/min.) & $20.13 \pm 2.19^{*}$ & $26.18 \pm 2.54$ & $\mathrm{P}<0.05$ \\
\hline
\end{tabular}

VC: Vital Capacity; MVV: Maximum Voluntary Ventilation; $\mathrm{SaO}_{2}$ : Arterial Oxygen Saturation; $\mathrm{VO}_{2}$ max: Maximum Oxygen Consumption; RR: Respiratory Rate; $(*)$ indicates a significant difference between the two groups, $\mathrm{P}<0.05$.

\section{Discussion}

This study was designed to determine the effect of pulmonary rehabilitation program on pulmonary function and exercise tolerance in subjects with Down syndrome. The same therapist and technique before the study and after 2 months of the study measured all the parameters of evaluation. It was reported that, subjects with DS have reduced peak and sub-maximal exercise capacity [23]. Our results proved that VC, $\mathrm{MVV}, \mathrm{SaO}_{2}$ and RR significantly improved at the end of the study because of the pulmonary rehabilitation program and these results are in agreement with some previous studies as well. While, Weiner et al. concluded in their study on comparative study between the effects of inspiratory muscle training combined with bicycle ergometer training with bicycle ergometer training alone on inspiratory muscle performance and general exercise capacity, 
Impact of Pulmonary Rehabilitation Program on Respiratory Function and Exercise Tolerance in ..

both training regimens increased maximal power output and oxygen intake, but the improvement was greater in the patients with inspiratory muscle training [24]. However, Normandin et al. proved that exercise training on treadmill, 3 sessions every week for 2 months improved twelve-minute walking test, MVV and VC in their population of study [25]. The explanation for the pulmonary function improvement after the rehabilitation program was based on mechanical bases as the improvement in $\mathrm{VC}, \mathrm{MVV}, \mathrm{SaO}_{2}$ and $\mathrm{VO}_{2 \max }$, mainly due to increase in thoracic cage diameters; vertical, lateral and anterior-posterior diameters of the chest[26]. Meanwhile, the improvement in VC mainly indicated an increase in the respiratory muscle mechanical efficiency to generate power and to inspire more deeply. However, improved efficiency and strength of the respiratory muscles are the underlying mechanism for the improvement in MVV value [27].

Regarding $\mathrm{VO}_{2 \max }$, our results revealed that exercise tolerance among DS subjects improved significantly following the pulmonary rehabilitation program which is in agreement with Strasseles et al. They mentioned that application of lower limb exercise training and respiratory muscles training led to improvement in quality of life as a result of control of dyspnoea [28]. In addition, Mahler mentioned that lower extremity exercise training was shown to control of dyspnoea and improved exercise tolerance. Improved lactate threshold and oxidative activity of the skeletal muscles along with dyspnoea control are the possible mechanisms for reduced severity of breathlessness and improved exercise capacity that enable patients to perform higher levels of work [27]. However Belman stated that, evaluation of exercise training for one hour, three times a week for eight weeks showed that limb training was limb specific. Thus, it was only in the group that trained with the upper extremity, in which the upper extremity endurance increased, while walk distance improved in the lower limb trained group. The walk distance improved in the lower limb trained group and the combination trained group showed improvements in both upper and lower limbs endurance [29]. Moreover, Tomohiro concluded that, moderate intensity exercise had a significant increase in $\mathrm{VO}_{2}$ max [30]. While, Tsimaras and colleagues were the first researchers who documented the significant improvement in the $\mathrm{VO}_{2 \max }$ among adults with DS as a result of aerobic exercise training of three/sessions every week for 3 months [31]. In addition, Rimmer et al. reported that 3 months of a combined exercise program similarly improved $\mathrm{VO}_{2 \max }$ among adults with DS [32]. Moreover, significant increase in $\mathrm{VO}_{2 \max }$ is related to improvement in respiratory function as vital capacity, inspiratory reserve volume and expiratory reserve volume and also stroke volume of the heart increased by regular exercises. This respiratory adaptation facilitates of oxygen supply to the tissues adds further evidence to the improvement of respiratory fitness [33].

\section{Conclusion}

The results of the present study concludes that, pulmonary rehabilitation program improves the respiratory functions and exercise tolerance in subjects with Down syndrome.

\section{References}

[1]. Irving C, Basu A, Richmond S, Burn J, Wren C. Twenty-year trends in the prevalence of survival in Down syndrome. Eur J Hum Genet. 2008; 16 (11):1336-1340.

[2]. Morris J, Alberman E. Trends in Down's syndrome live births and antenatal diagnoses in England and Wales from 1989 to 2008: analysis of data from the National Down Syndrome Cytogenetic Register. BMJ. 2009; 339: b3794.

[3]. Pitetti KH, Boneh S. Cardiovascular fitness as related to leg strength in adults with mental retardation. Med Sci Sports Exerc. 1995; 27(3):423-428.

[4]. Fernhall B, Pitetti K. Limitations to physical work in individuals with mental retardation. Clin Exerc Physiol. 2001; 3:176-185.

[5]. Baynard T, Pitetti KH, Guerra M, Unnithan VB, Fernhall B. Age-related changes in aerobic capacity in individuals with mental retardation: a 20-yr review. Med Sci Sports Exerc. 2008; 40(11):1984-1989.

[6]. Pitetti KH, Climstein M, Mays MJ, Barrett PJ. Isokinetic arm and leg strength of adults with Down syndrome: A comparative study. Arch Phys Med Rehabil. 1992; 73(9):847-850.

[7]. Carmeli E, Barchad S, Lenger R, Coleman R. Muscle power, locomotor performance and flexibility in aging mentally-retarded adults with and without Down's syndrome. J Musculoskelet Neuronal Interact.2002; 2(5):457-462.

[8]. Carmeli E, Kessel S, Bar-Chad S, Merrick J. A comparison between older persons with Down syndrome and a control group: clinical characteristics, functional status and sensoriomotor function. Downs Syndr Res Pract. 2004; 9(1):17-24.

[9]. Kober R, Eggleton IR. The effect of different types of employment on quality of life. J Intellect Disabil Res. 2005; 49(Pt 10):756760.

[10]. Stephens DL, Collins MD, Dooder RA. A longitudinal study of employment and skill acquisition among individuals with developmental disabilities. Res Dev Disabil. 2005; 26(5):469-486.

[11]. Fernhall B, Pitetti KH, Rimmer JH, et al. Cardiorespiratory capacity of individuals with mental retardation including Down syndrome. Med Sci Sports Exerc. 1996; 28(3):366-371.

[12]. Baynard T, Pitetti KH, Guerra M, Unnithan VB, Fernhall B. Age-related changes in aerobic capacity in individuals with mental retardation: a 20-yr review. Med Sci Sports Exerc. 2008; 40(11):1984-1989.

[13]. Fernhall B, Tymeson G, Millar L, Burkett N. Cardiovascular fitness testing and fitness levels of adolescents and adults with mental retardation including Down syndrome. Educ Train Ment Retard. 1989; 24:133-138.

[14]. Roland T. The development of aerobic fitness in children. In: Armstrong N, Kirby B, Welsman J, editors. Children and Exercise XIX. Promoting Health and Well-being. $1^{\text {st }}$ ed. London, UK: Chapman \& Hall; 1997:179-190.

[15]. Pitetti KH, Climstein M, Campbell KD, Barrett PJ, Jackson JA. The cardiovascular capacities of adults with Down syndrome: a 
comparative study. Med Sci Sports Exerc. 1992; 24(1):13-19.

[16]. Marder E. and Dennis J. "Medical management of children with Down's syndrome". Current Pediatrics. 2001; 11:57-63.

[17]. Prasad S and Hussey S. "Chest physiotherapy techniques" In: Prasad S. A. and Hussey, S. A., Ed.: "Pediatric respiratory care, a guide for physiotherapists and health professionals" London: Chapman \& Hall.1995; P: 67-104

[18]. Vedantam R., Lenke L. and Haas J. A prospective evaluation of pulmonary function in patients with adolescent idiopathic scoliosis relative to the surgical approach used for spinal arthrodesis. Spine.2000; 25 (1): 82-90.

[19]. Bipin P, Mohamed Faisal C K, Renuka D M, Ajith S. Efficacy of Active Cycle of Breathing Technique and Postural Drainage in Patients with Bronchiectasis- A Comparative Study. Innovative J Med and Health Sciences. 2012. 2(6); 129-132.

[20]. Junaid A F, Ajith S, Mirajkar A M, Mohamed Faisal C K, Ivor P D'Sa. Effect of Midprone Decubitus on Pulmonary Function Test Values in Young Adults with undesirable Body Mass Indices (BMI). Indian Journal of Physiotherapy \& Occupational Therapy. 2013; 7(1); 280-284.

[21]. Stanley John Winser, Priya Stanley, George Tarion. Respiratory rehabilitation with abdominal weights: a prospective study. Scientific Research. 2010; 2(5):407-11.

[22]. Sathish G., Anilkumar P., Elanchezhian C., Rishikesavan R. Effectiveness of resisted abdominal exercise versus resisted diaphragmatic breathing exercise on cardiovascular endurance in sports men. Int J Med Res Health Sci. 2014; 3(4):785-789.

[23]. Mendonca G, Pereira F, and Fernhall B. Reduced exercise capacity in persons with Down syndrome: cause, effect, and management. Ther Clin Risk Manag. 2010; 6: 601-610.

[24]. Weiner P, Azgad Y, Ganem R. Inspiratory muscle training combined with general exercise reconditioning in COPD. Chest. 1993. 124:396-400.

[25]. Normandin E, Mccusker C, Conners M. An evaluation of two approaches to exercise conditioning in pulmonary rehabilitation. Chest. 2002. 121:1085-1091.

[26]. Ajith S, Ivor P D'Sa, Mohamed Faisal C K, Anandh V, Sreejith N. Physiological Cost Index (PCI) in Patients with Chronic Obstructive Pulmonary Disease (COPD) before and after giving two commonly used Breathing Exercises. International Journal of Current Research and Review. 2011; 3(12); 41-48.

[27]. Mahler D. Pulmonary rehabilitation. Chest.1998. 113: 263S-268S.

[28]. Strasseles S, Smith D, Mahajan P. The costs of treating COPD in the United States. Chest. 2001. 119:344-352.

[29]. Belman M. Exercise in patients with chronic obstructive pulmonary disease. Thorax. 1993. 48:936-946.

[30]. Tomohiro O, Yoshio N, Kiyoji T. Effects of exercise intensity on physical fitness and risk factors for coronary heart disease. Obesity. 2003. 11:1131-1139.

[31]. Tsimaras V, Giagazoglou P, Fotiadou E, Christoulas K, Angelopoulou N. Jog-walk training in cardiorespiratory fitness of adults with Down syndrome. Percept Mot Skills. 2003; 96 (3 Pt 2): 1239-1251.

[32]. Rimmer JH, Heller T, Wang E, Valerio I. Improvements in physical fitness in adults with Down syndrome. Am J Ment Retard. 2004; 109 (2):165-174.

[33]. Carsten J, Christina K, Jens J, Peter K. Effect of high intensity intermittent training on lactate an H release from human skeletal muscle. Am J Physiol Endocrinol Metab. 2004. 286:245-251. 